\title{
Education and training
}

\section{Notes on the Lundbeck Teaching Fellowship to Bulgaria 1991}

\author{
DAvid Storer, Consultant Liaison Psychiatrist; and Dorothea Holman, \\ Consultant Child and Adolescent Psychiatrist, The General Infirmary at Leeds, \\ Great George Street, Leeds LS1 3EX
}

In 1991 the Royal College of Psychiatrists awarded two overseas teaching fellowships. Tom Harrison and Alexandra Espejo described their visit to Chile in the March 1993 Psychiatric Bulletin. We were asked to visit Bulgaria to teach liaison psychiatry in both child and adolescent and adult psychiatry.

\section{The seminars}

We held week-long programmes of seminars in Sofia in November 1991. The content and references were agreed and supplied in advance and covered a wide range of topics in liaison psychiatry. The participants for the adult psychiatry seminars had travelled from the cities of Plovdiv and Russe as well as Sofia. In age and experience they varied from two senior medical students to an Assistant Professor. In child psychiatry the audience was multidisciplinary. Daily meetings took place in the Institute of Hygiene which is part of the medical academy in Sofia. The atmosphere was informal and the discussions included presentations of cases and their management.

The Bulgarian colleagues showed great interest in the way psychiatry was practised in the United Kingdom and also postgraduate training for psychiatrists, organisation of services and the career structures and training of other disciplines. There are no occupational therapists in Bulgaria and only very occasionally social workers are employed in the service. The nursing staff are general nurses, not specially trained in mental health.

We were always late for lunch and finished later than arranged in the afternoon sessions. Even on the day our Bulgarian colleagues were due to collect their salaries, which they had not received for several months, they were very apologetic for having to leave on time. They all understood English and some spoke it very well.

\section{Visits to psychiatric facilities}

The visits to the various units were interesting and instructive. We met the nurses and other doctors

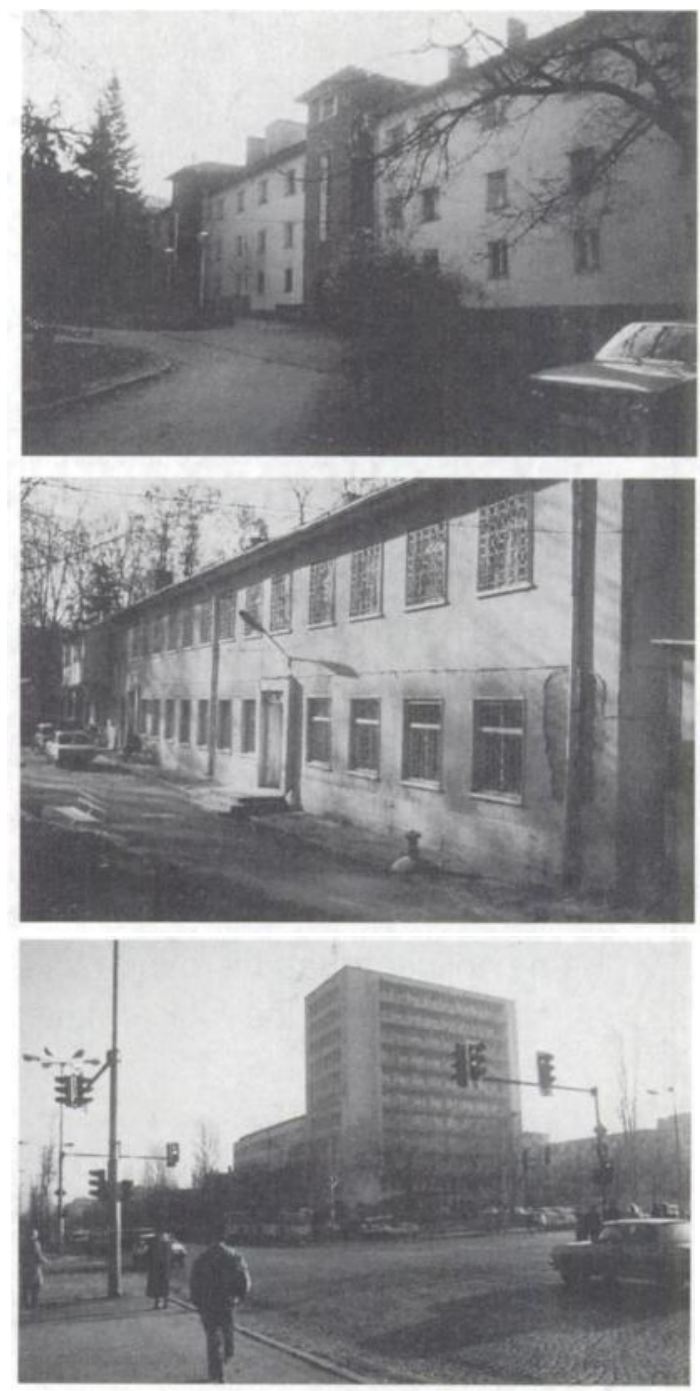

Top: 'Neurosis Unit', Psychiatric Hospital, Sofia, middle: Admission Ward, Psychiatric Hospital, Sofia; bottom: Accident Hospital, Sofia 
working in in-patient units and discussed with them the management of the patients they presented.

The facilities in which our Bulgarian colleagues worked varied from those in the out-patient department of the academic unit, which would be the envy of most of us, to some comparable with those described by Radhakrishnan (1991).

\section{Conclusions}

From the visit we came away full of admiration for our Bulgarian colleagues whose conditions of work are far from easy considering the lack of standing of psychiatry compared to other specialities, the lack of investment in manpower and services, and the situation in a country undergoing profound political changes which inevitably affected the professions and patients alike. This visit made us more appreciative of our own services and highlighted the similarities between the problems which children, adolescents and families have independent of the social and cultural milieu and the issues that psychiatry has to deal with in relation to other specialities. The differences seem to be seated more in customs, traditions and social system than in understanding of the problems.

We would like to encourage colleagues to take an interest in the developments in Eastern Europe and offer support to our colleagues there from their position of working in a comparatively more stable and better endowed system. The most useful contacts seem to be through small teams exchanging practical experience where both sides can learn from each other, and in offering our expertise in the organisation of postgraduate education.

\section{Reference}

RADHAKRISHNAN, G. (1991) Mental health services in Romania. Psychiatric Bulletin, 15, 621-623.

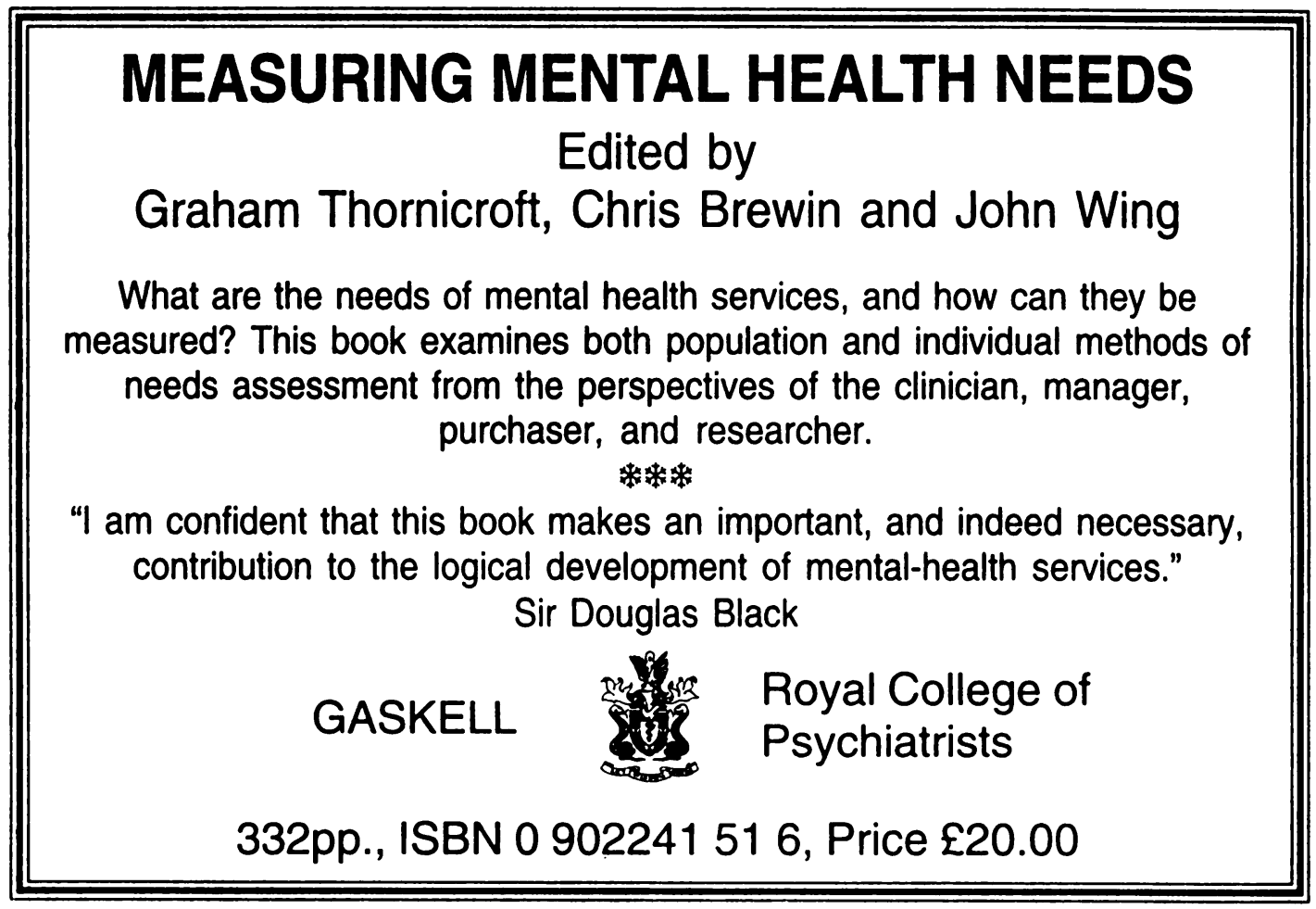

